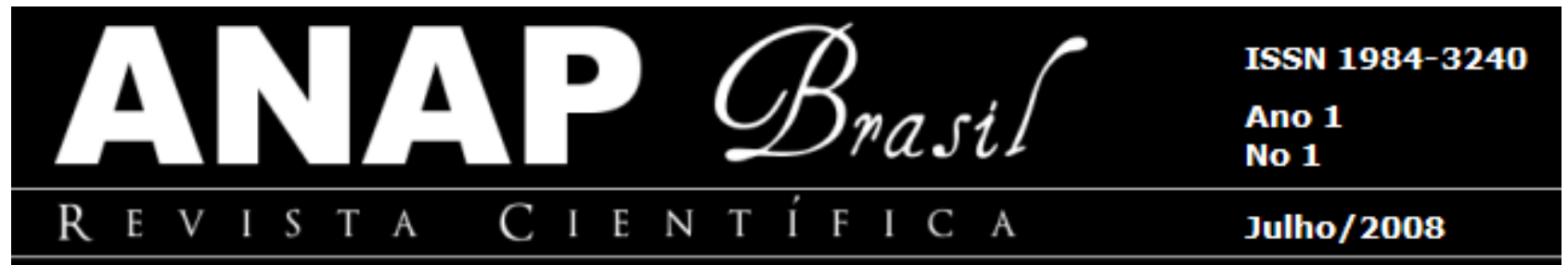

\title{
ECOLOGIA, FILOSOFIA E EDUCAÇÃO. DIÁLOGOS TRANSDISCIPLINARES NA PERSPECTIVA DA SUSTENTABILIDADE.
}

\author{
Lesly Monteiro Ratinho
}

RESUMO: Este estudo tem como objetivo desenvolver uma reflexão sobre como a filosofia pode ajudar a educação a compreender os temas ambientais. Para tanto, se torna necessário entender a ruptura entre as Ciências Naturais e as Ciências Humanas, e questionar se é possível uma nova conexão destas epistemologias visando à quebra do paradigma antropocêntrico arraigado no ser humano. Uma integração dos diferentes saberes instituídos poderia modificar pensamentos, sentimentos, palavras e ações para a defesa da sustentabilidade planetária? A hermenêutica é uma disciplina filosófica em que se discutem a interpretação de idéias e pensamentos. A palavra deriva do nome do deus grego Hermes, o mensageiro dos deuses, a quem se atribui à mediação da linguagem e do entendimento entre os mundos. Pode a hermenêutica ser utilizada como agente construtor de reflexões, explicitando as temáticas ambientais tão necessárias à manutenção da vida humana no planeta? Por ser a hermenêutica uma disciplina e por este estudo ter um movimento de quebra de barreiras, a transdiciplinaridade é analisada como um processo que pode levar o ser humano a compreender o mundo e sua inserção nele de maneira diferente do habitual. A transdiciplinaridade instrumentaliza o diálogo entre a ecologia, a filosofia e a educação além de passar (e ultrapassar) outros campos epistemológicos. Já a teoria de Gaia é apresentada com o intuito de alargar a concepção do papel da espécie humana no planeta Terra e também como um instrumento de viabilização para a reflexão em sala de aula.

Palavras-chave: Filosofia, Hermenêutica, Transdiciplinaridade

\section{INTRODUÇÃO}

Este estudo tem como objetivo desenvolver uma reflexão sobre como a filosofia pode ajudar a educação a compreender os temas ambientais. Para tanto, se torna necessário entender a ruptura entre as Ciências Naturais e as Ciências Humanas, e 


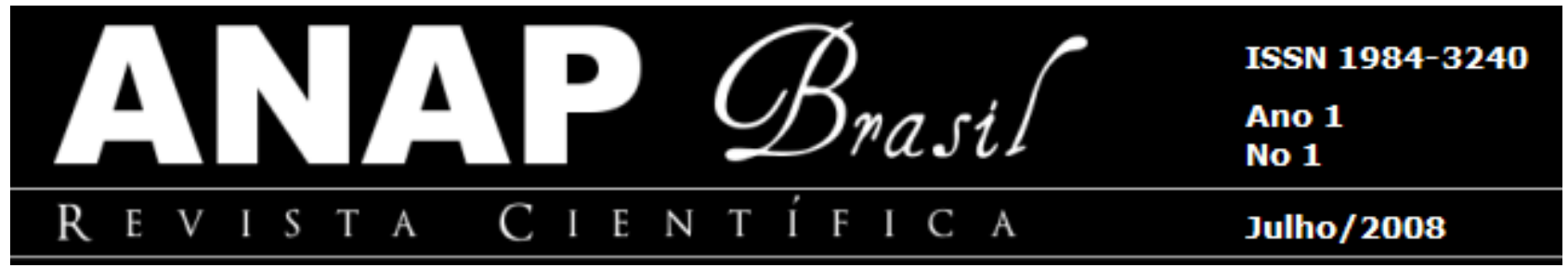

questionar se é possível uma nova conexão destas epistemologias visando à quebra do paradigma antropocêntrico, e a integração dos diferentes saberes instituídos em defesa da sustentabilidade planetária.

Praticamente todos os dias vemos nos noticiários as catástrofes ambientais. Os números absurdos infelizmente não cogitam mudanças políticas, econômicas e sociais. Assim assistimos à bola de neve da impassividade ser repassada às próximas gerações. Até quando seremos criados e educados para transformar o mundo e toda a sua rica variedade de detalhes em "saber habitual", padronizado e enlatado à venda nas prateleiras das lojas?

Dessa forma, torna-se relevante e necessário estudar o discurso educacional, filosófico e, portanto ambiental para percebermos que somos seres que compartilhamos um só destino.

Numa análise bibliográfica de 20 obras, três temas foram aprofundados: correntes filosóficas com seus paradigmas, educação ambiental com seus conceitos primários/secundários e a transdisciplinaridade com suas perspectivas sustentáveis.

\section{DESENVOLVIMENTO}

Criou Deus, pois, o homem à sua imagem, à imagem de Deus o criou; e Deus os abençoou e Ihes disse: sede fecundos, multiplicai-vos, enchei a terra e sujeitai-a; dominai sobre os peixes do mar, sobre as aves dos céus e sobre todo animal que rasteja pela terra $[\ldots]^{1}$ (grifo nosso)

Para alguns, desde o início o "homem" vê-se determinado a ser o dominador do planeta e de todas espécies nele contida, afinal é o filho do Criador.

As palavras de Deus contidas nos textos sagrados foram inquestionáveis, para outros, até o surgimento das ciências modernas, onde a razão, a lógica, o cientificismo é que deveriam governar o mundo contemporâneo.

\footnotetext{
${ }^{1}$ Gênesis, primeiro capítulo da Bíblia, livro sagrado dos católicos.
} 


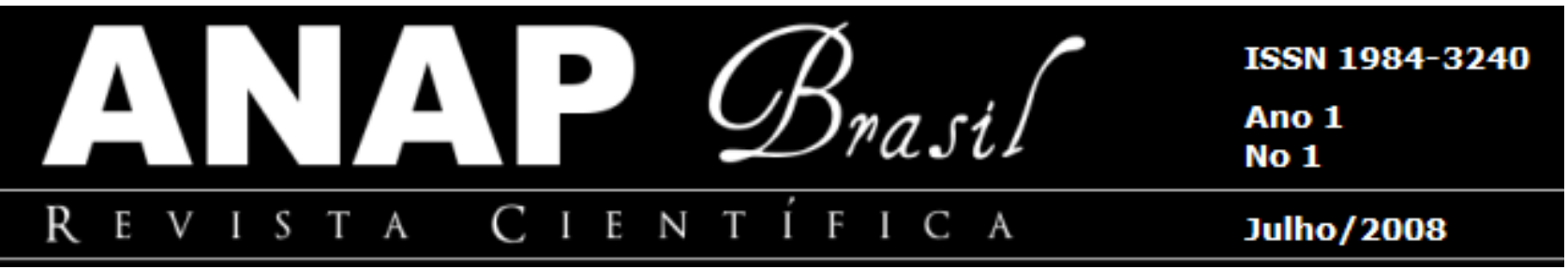

A incrédula Ciência afirma ser capaz de explicar a realidade, mesmo que não haja uma única resposta, os cientistas de nossa história sedentos por dados objetivos criam metodologias para fundamentar e produzir os mais diversos conhecimentos que salvarão os seres pensantes de uma possível revolta e dominação das outras espécies.

No entanto, em alguns pontos, os intelectuais humanistas se parecem com fundamentalistas religiosos, ambos desejam o domínio da natureza para saciar suas necessidades, seus prazeres e desejos.

Grün (1996) ao explicar o modelo ideológico do Mundus Alter - o Novo Mundo de Francis Bacon, descreve claramente como a visão cientificista que nos antecedeu deixou marcas profundas na maneira de pensar o mundo.

O entusiasmo e o otimismo baconianos professavam que o Homem deveria ser o senhor de seu destino e isso, é claro, implicava que ele fosse o mestre e senhor de todas as coisas do mundo. Assim, a perspectiva baconiana de uma nova cultura carregava em seu bojo um antropocentrismo radical. O projeto "moderno" de Bacon fracassou. A humanidade não se tornou inteiramente livre por meio da ciência como imaginava Bacon. No entanto, a contraface de seu projeto triunfou de um modo surpreendente e o antropocentrismo passou a integrar o cerne do corpo da concepção de ciência na época moderna. (GRÜN, 1996, p.32)

A visão antropocêntrica está incorporada nos pensamentos, sentimentos e comportamentos humanos desde as suas primeiras reflexões em sociedade, o que torna difícil fazer com que o ser humano perceba sua real e pequena participação planetária.

A contínua produção de conhecimentos científicos serve para contribuir com uma vida melhor para todos, mas como anunciou Grün a mesma ciência que produz, escraviza. Giacoia Junior (2204) também processa o mesmo pensamento, ele diz que a dominação da ciência tornou os homens os "senhores dos elementos".

[...] os progressos alcançados no domínio da física nuclear e da química transformaram o homem no "senhor dos elementos", desarraigado-o da terra e abrindo horizontes para a exploração...com isso, o homem teria enfim conquistado a sempre sonhada supremacia sobre todas as criaturas...senhor das ciência e da técnica, ele poderia doravante tomar integralmente nas próprias mãos a planificação e o controle das condições de existência no planeta." (GIACOIA, 2004, p.639) 


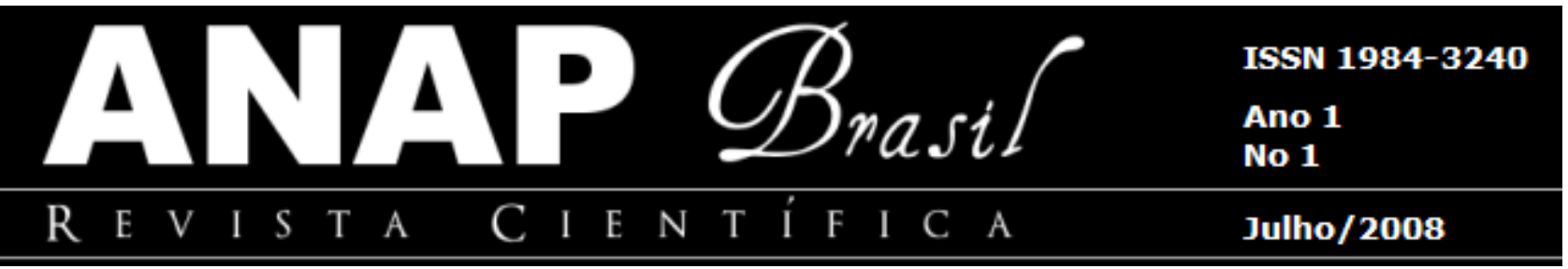

Desta forma encontramos normatizações e metodologias que nos conduzem a uma comunidade de robôs, sem singularidades ou reflexões profundas, acontece que não existe pensamento humano homogêneo.

A ciência então se divide para melhor encaixar-se na rotina social, e assim temos a ciência natural que servirá para explicar todos os fenômenos, e a ciência humana que terá como função compreender outros tantos. A combinação seria eficaz caso houvesse uma integridade em ambas, todavia elas não dialogam por necessitarem vencer a corrida que levará a verdade absoluta, mas como diz o poeta, "A verdade absoluta é uma somatória de todas as mentiras".

A dicotomia é inerente à quebra de uma possível conexão entre diferentes faces de uma mesma realidade, assim temos de visualizar ora um sujeito, ora um objeto para fazer ciência. Mas antes mesmo da existência da ciência ou da idéia de dados objetivos encontramos um planeta que tem vida própria e segue sua evolução.

Num determinado momento da historia planetária, o ser vivente dominante eram os poderosos microorganismos, que por muitos anos foram os únicos aproveitadores do ambiente, depois tivemos outros que "consideravam-se os donos do mundo", como os dinossauros e o homem. Mas todos eles são apenas mais uma espécie que "mora de aluguel" na casa chamada Terra.

Os homens e as mulheres, chamados de seres pensantes precisam perceber que não são nem donos nem protetores do planeta, porque o fenômeno da vida está em escala planetária e a evolução diz respeito à Gaia.

Já sabemos da impossibilidade de ocorrer uma verdade absoluta, ou seja, a guerra de ideologias é insana, no entanto há um planeta absoluto que recebe drasticamente a influência das produções humanas que remetem às alterações climáticas, que por sua vez tornarão impróprio a habitação da espécie humana na biosfera terrestre.

Se somos inquilinos inconseqüentes precisamos de um senhorio que nos mostre regras justas, e esse senhorio já bate a nossa porta a algum tempo, mas nosso medo de mudar os "prazerosos e costumeiros hábitos" nos impede de abrir a mente para refletir que existe algo a mais do que nosso egocêntrico jeito de ser. Lovelock (1995) em uma de suas explanações resume a nossa situação: 


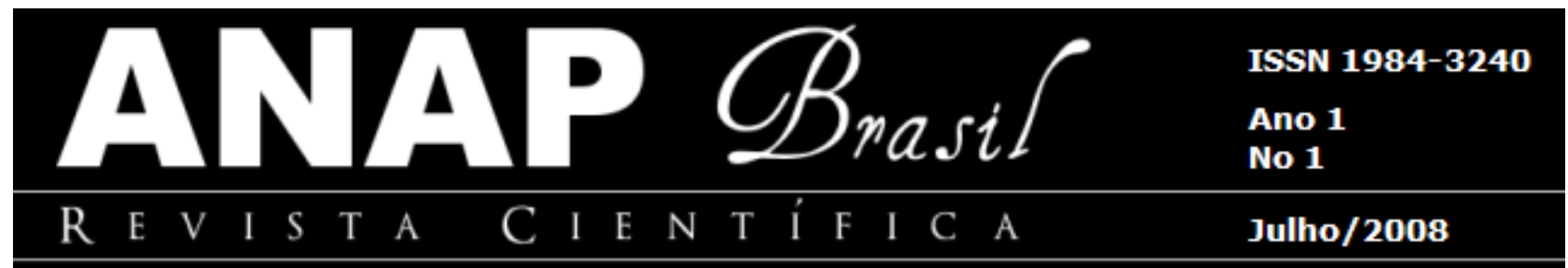

Vista da escala de tempo de nossas vidas breves, a mudança ambiental deve parecer acidental ou parte maligna. A partir da imensa perspectiva de Gaia, a evolução do ambiente é caracterizada por períodos de êxtase, com intervalos de mudança abrupta e repentina. O ambiente nunca foi tão desconfortável que chegasse a ameaçar a extinção da vida na Terra, mas durante essas mudanças abruptas as espécies residentes sofreram catástrofes, cuja escala faria com que uma guerra nuclear total parecesse, em comparação, uma coisa tão banal quanto a brisa de verão é para um ciclone. Nós somos o produto de uma catástrofe dessas. Será que sem querer estamos precipitando mudanças que irá alterar o ambiente, para que ele se adapte aos nossos sucessores? (LOVELOCK, 1995, p.146)

Precisamos perceber que somos seres que compartilhamos um só destino. Precisamos pensar que há outras faces a serem desvendadas, e que o "ponto de vista do planeta Terra" é mais importante que nossa insignificante filosofia humana. Somos uma coletividade de seres, e assim devemos pensar que para termos liberdade devemos lembrar de "preservar", para a nossa sobrevivência, o planeta, que não está diante nem da primeira e nem da ultima espécie que usufrui seu ambiente.

James Lovelock (1995) consegue expor sua teoria de forma clara remetendo a espécie humana o seu verdadeiro valor no planeta.

Temos de nos lembrar que em Gaia a evolução dos organismos e seu ambiente constituem um processo único e conjunto. Além do mais, os ciclos de todos os elementos que constituem Gaia estão estreitamente associados entre si e também com as espécies dos organismos. (LOVELOCK 1995, p.126)

Como a palavra "teoria" tem a mesma raiz grega que "teatro", para Lovelock elas "dizem respeito a um espetáculo. Uma teoria em ciência, não é senão aquilo que parece ao seu autor uma forma plausível de vestir os fatos para apresentá-los à platéia" (1995, p. 39).

Assim, condicionados e presos ao estilo cientificista de sobreviver, devemos adequar as descobertas para explicitar o que está implícito por detrás dos interesses humanistas vindouros à contemporaneidade.

Será que as antigas questões perderam as forças? Quem somos, de onde viemos e para onde vamos não fazem mais parte da curiosidade humana e a preocupação contemporânea é produzir e consumir o mundo material? Pelizzoli (1999) levanta o 


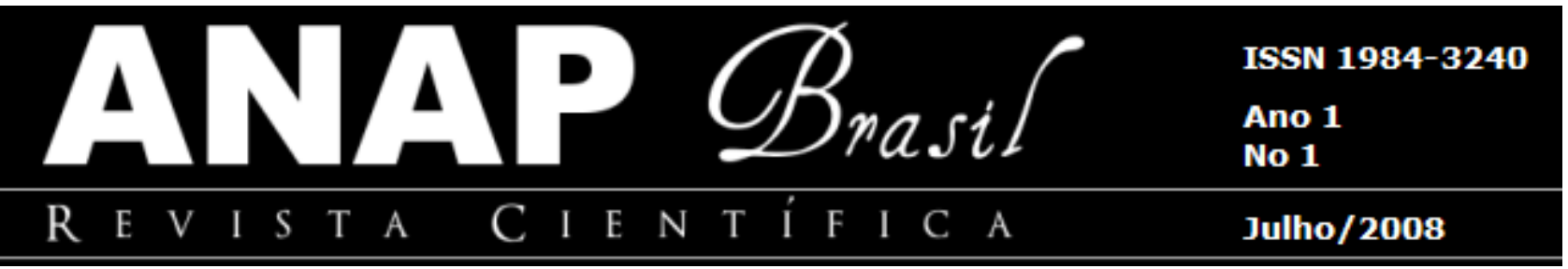

debate da ética e pergunta onde está a sensibilidade que nos tornava unidos com o cosmos. A revolução científica sufocou nossa poesia e precisamos resgatá-la para nos compreender melhor.

A noção de cosmo (harmonia, beleza, universo, todo dinâmico) é fundamental. O homem se debruça de fato para conhecer e integra-se no processo da natureza, em suas oposições. O homem é parte do cosmo; é o "ser-no-mundo", na casa, e deve associar-se aos processos naturais, ao mesmo tempo que buscar desvendálos. (PELIZZOLI, 1999, p.55)

A filosofia como instrumento primordial dos questionamentos humanos poderia ser o caminho para a não normatização dos sujeitos, e sim para uma real emersão da reflexão praticada em ações diárias e independentes do locus social.

Ao passar pelas reflexões da Hermenêutica, que postula explicar e compreender o impensado usando como meios a linguagem, podemos vislumbrar um caminho para trabalhar a educação ambiental com os discentes. Para a hermenêutica aquilo que pensamos manifesta-se em palavras que gerarão ações. Assim, para modificarmos nossas ações devemos modificar nossos pensamentos que por sua vez serão despertados pelas palavras.

Para Grün (1996), a hermenêutica tem um forte significado:

A hermenêutica filosófica situa sempre o ser humano no mundo, na história e na linguagem e não como um sujeito senhor de si, separado dos objetos. Os seres humanos estão sempre inexoravelmente inseridos no circulo hermenêutico. (GRÜN, 1996, p.102)

A hermenêutica diz que o homem constrói sua história pelos símbolos e mitos criados, que ocasionam significações de uma linguagem filosófica.

Nos dicionários encontramos a hermenêutica como a interpretação do sentido das palavras, das leis, dos textos, mas segundo Hermann (2003) a hermenêutica vai além.

A hermenêutica ressurge modernamente no contexto de luta contra a pretensão de haver um único caminho de cesso à verdade. No ambiente cientificista da modernidade, se estabeleceu o predomínio do positivismo, que se apóia em dados objetivos como procedimento válido para produzir conhecimento. Contra isso, a hermenêutica quer demonstrar que não há mais condições de manter o monismo metodológico, uma forma exclusiva de determinar o espaço de produção do 


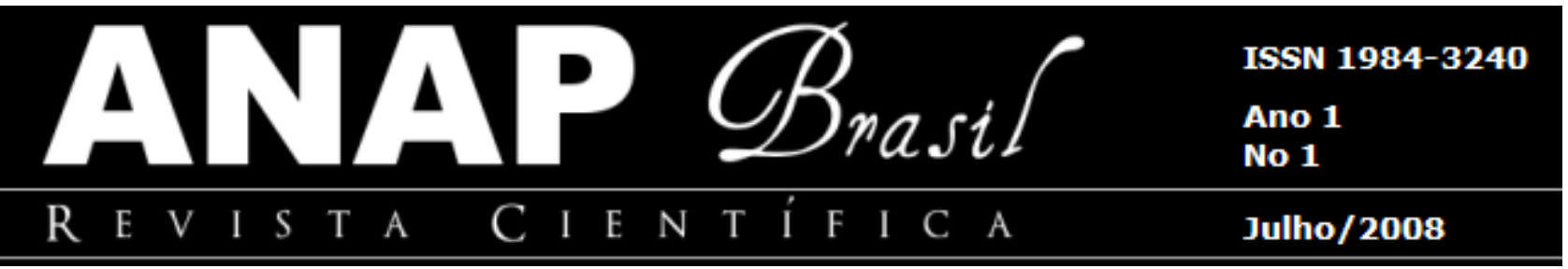

conhecimento. Além do método cientifico, há outras formas de conhecer a realidade. (HERMANN, 2003, p.15)

A hermenêutica possui um discurso transdisciplinar que também é o discurso ambiental, ambas podem proporcionar ao aluno uma pedagogia que dialogue mais com os sentidos do que com a lógica.

Como a hermenêutica com o seu traduzir o oculto, o exotérico, pode levar à educação formal e não formal uma visão mais presente e respeitosa do ambiente que fazemos parte?

Nádia Hermann indica alguns passos quando diz que "a hermenêutica pode ajudar no meio ambiente quando ajudando o homem a interpretar a realidade que está além de seu umbigo, trazendo à tona aquilo que está escondido atrás do modo "materialista" de se viver." (2003, p.24)

Pensar conscientemente nas gerações futuras e passadas para que eles dialoguem com o presente, e então os erros passados possam ser assimilados e as conseqüências futuras imaginadas e pré-sentidas.

Vivemos em uma civilização que conseguiu ignorar completamente a mais fundamental de todos as questões - sua própria sustentabilidade, ou seja, as próprias condições de possibilidades do futuro humano. (GRÜN, 1996 pg.111).

Por acreditar não existir metodologias, receitas ou cartilhas que levarão os educadores a alcançar resultados fundamentalmente ético-socioambientais, já que sua influência é pequena diante da complexidade do educar, que tem um sentido de diversidade, coletividade, e não pode ser encaixado numa identidade igualitária global, reajustes às linguagens, aos mitos e aos símbolos são essenciais para despertar uma reflexão do que significa estar vivenciando a experiência humana, conforme nos mostra Carvalho em suas reflexões:

Os seres humanos relacionam-se também, com outros seres da realidade, que não são seres humanos: essas relações, por sua vez, são modificadoras dos seres humanos, e, portanto, em certo sentido, educadores. (CARVALHO, 2002, p.27 in 2004 p.137). 


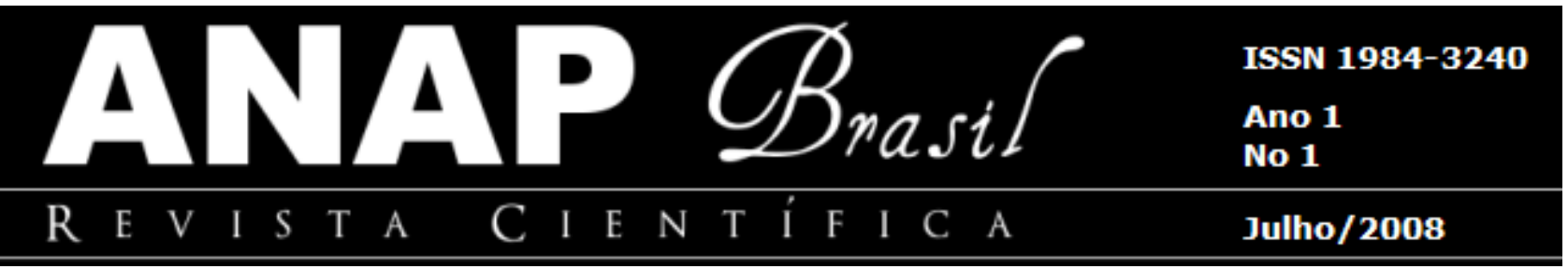

Apenas aqueles que refletem podem ser atemporais e ao mesmo tempo ambientais, no sentido mais complexo desta palavra e a educação ambiental como instrumento despertador das visões cristalizadas torna-se essencial para compreendermos a realidade em que estamos inseridos.

Para fazer o dialogo entre a ecologia, a filosofia e a educação e portanto fazer o cruzamento dos levantamentos epistemológicos desta pesquisa, utilizaremos a transdiciplinaridade, termo que surge na década de 70 em trabalhos simultâneos de JeanPiaget, Edgar Morin, Eric Jantsch, entre outros. Um de seus significados é "transgredir as fronteiras entre as disciplinas".

Os estudos da transdiciplinaridade surgem concomitante à revolução quântica e à revolução da informática que de certa maneira são resultantes da insatisfação humana de viver sob a ótica unilateral das ciências clássicas.

Ambas revoluções têm como uma de suas funções diminuir o tempo gasto com a competitividade pela sobrevivência e liberar o tempo para, com diz Basarab, "consagrarmos a vida".

No entanto aquilo que poderia ser um ganho planetário com a troca de diferentes conhecimentos em "velocidade da luz" tornou-se mais um jogo de poder, onde quem tem as informações domina a política, a economia e as culturas ignorantes desses saberes.

Os saberes são hoje em maior número do que antes, as disciplinas aumentaram, mas a evolução do conhecimento que deveria abrir nossa mente, nos enriquecer conscientemente, nos deixa cada vez mais cegos para a realidade e nos envolve em uma teia de ilusões.

Basarab (1999) faz perguntas importantes, ele diz:

Como se explica que quanto mais sabemos do que somos feitos, menos compreendemos quem somos? Como se explica que a proliferação acelerada das disciplinas torne cada vez mais ilusória toda a unidade do conhecimento? Como se explica que quanto mais conheçamos o universo exterior, mais o sentido de nossa vida e de nossa morte seja deixado de lado como insignificante e até absurdo? ...De onde vem a loucura assassina do ser humano? (BASSARAB,1999, pg.16)

Parece que há uma luta entre conhecimento e sabedoria já que não é regra ao nos apoderamos de um conhecimento nos tornemos mais sábios e coerentes por isso. 


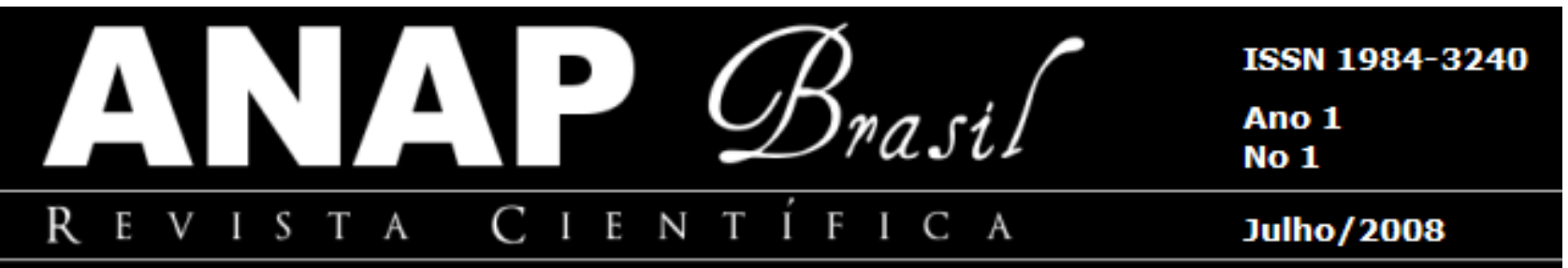

Nossas atitudes, sentimentos e pensamentos parecem não ser afetados pelos saberes que adquirimos.

Mas a luta pela sabedoria deve ser travada, pois está em jogo a sobrevivência da espécie humana e do planeta.

A visão exclusivamente objetiva dos fenômenos naturais, a ignorância da subjetividade, o olhar insensível diante das catástrofes humanas, o esquecimento da universalidade pode levar a raça humana para um "fim estúpido", e esta autodestruição se dará através das próprias invenções estimuladas pelo desenvolvimento dos saberes.

Basarab fala de uma tripla destruição em nome de valores escolhidos que foram vividos nos últimos tempos pelo cientificismo e a dominação da natureza.

Essa tripla destruição potencial - material, biológica e espiritual - é, na verdade, o produto de uma tecnociência cega mas triunfante, que só obedece à implacável lógica da eficácia pela eficácia. Mas como pedir a um cego que enxergue? (lbidem, pg.18)

Se a visão de mundo não for ampliada, realmente poderá ser tarde demais para humanidade e seus conhecimentos fragmentados, no entanto é justamente o trabalho mais abrangente com os conhecimentos já adquiridos que darão a continuidade sustentável da sociedade.

Bassarab fala da separação do homem e da natureza, ou a separação do sujeito e do objeto que trouxe ao mesmo tempo problemas e soluções para a evolução da espécie.

As soluções estão no campo da razão, o progresso continuado da física clássica produziu ordens que dão "sentido ao Universo", postulou-se:

- A existência de leis universais, de caráter matemático;

- A descoberta destas leis pela experiência científica;

- A reprodutibilidade perfeita dos dados experimentais.

A idéia de continuidade das leis está intimamente ligada a idéia de causalidade, gerando desta forma um pensamento determinista dos fenômenos. O homem poderia entender a natureza dos fatos e controlar as conseqüências previstas, desta forma poderia através das ciências tornar-se "o dono da verdade".

Os problemas surgem exatamente pela hegemonia desta crença, Bassarab critica "nosso jeito assassino de ser"; 


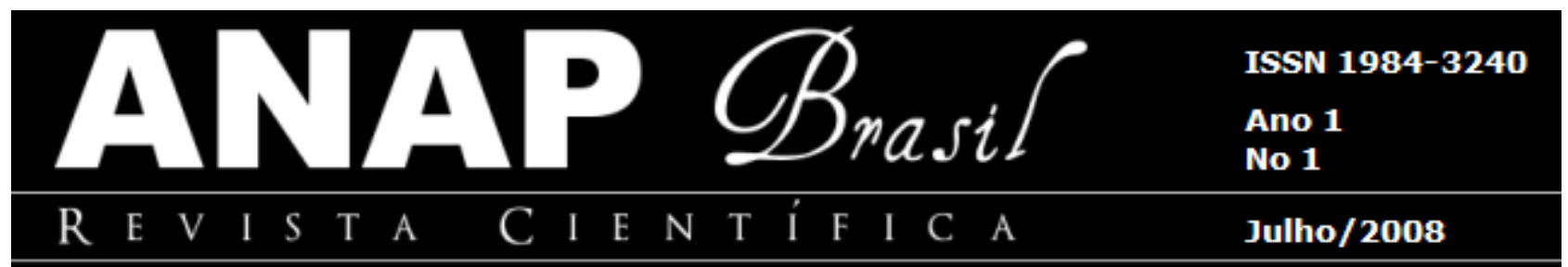

Se o Universo não passasse duma máquina perfeitamente regulada e perfeitamente previsível, Deus poderia ser relegado à condição de simples hipótese, não necessária para explicar o funcionamento do Universo. $O$ universo foi subitamente dessacralizado e sua transcendência jogada nas trevas do irracional e da superstição. (Ibidem, pg.22)

Ao citar Deus nessa frase, não significa que o autor defenda uma visão de mundo, e conseqüentemente uma educação de caráter religioso. A laicização nas aquisições de conhecimento é necessária para manter um rigor reflexivo, mas não se deve manter uma racionalidade fria para conhecer e compreender os fenômenos físicos.

A espiritualidade é um fator humano e por isso deve ser objetiva, mas devemos sempre questionar os dogmas, além de não descartar aquilo que não se consegue explicar.

A ciência jogou os conhecimentos apenas no campo da objetividade, desprezando a subjetividade e classificando-a como produto da imaginação, este movimento teve uma conseqüência inevitável: "A transformação do sujeito em objeto".

O ser humano torna-se objeto: objeto da exploração do homem pelo homem, objeto de experiências de ideologias que se anunciam cientificas, objeto de estudos científicos para ser dissecado, formalizado e manipulado. O homem-Deus é um homem objeto cuja única saída é se autodestruir. (ibidem, pg.23)

É a ciência transformando o homem e o homem transformando a ciência em mecanismo de destruição.

Já a física quântica fala de "descontinuidade", de indeterminismo, ou seja da impossibilidade de se prever resultados e por isso quebra com a ilusão humana de onisciência.

Um pensamento oposto da realidade instituída, que fora testada e comprovada e, portanto legitima outro paradigma que depende de inúmeros fatores e de uma pluralidade de valores para chegar a idéia de: nas partes encontramos o todo e no todo encontramos as partes interagindo continuamente na evolução do conjunto do sistemas naturais. 


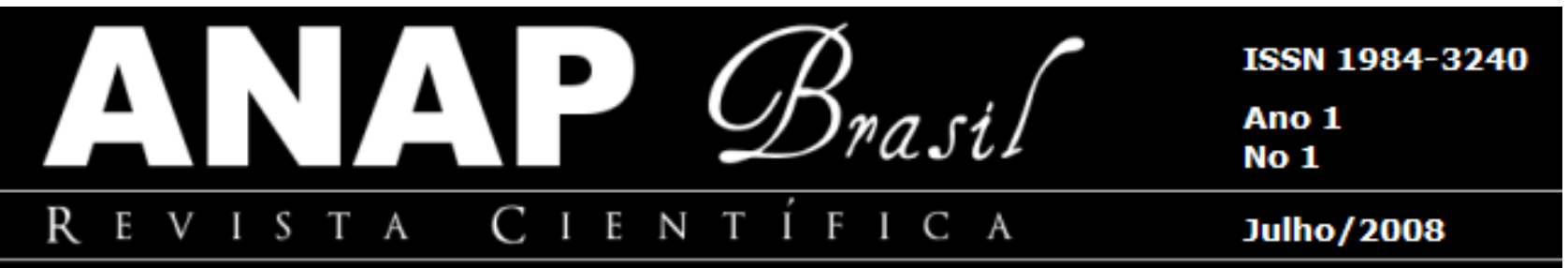

Este pensamento é a base para se pensar a transdiciplinaridade, a escala quântica que vai do infimamente pequeno ao infinitamente grande, que engloba a possibilidade do impensado, que mesmo o não observado é fator relevante para o desenvolvimento da realidade (ou das realidades), faz com que possamos enxergar as qualidades e os limites das disciplinas humanas e desejemos, desta forma, trabalhar com a "trans" que está além daquilo que conseguimos enxergar.

Pensar em níveis de realidade diferentes traz a possibilidade de agirmos no mundo também de forma distinta e este é o objetivo de uma educação transdisciplinar.

Para o paradigma cientificista os opostos são excludentes, ou somos contínuos, ou somos descontínuos, ou somos únicos, ou somos diversos, ou somos previsíveis, ou somos imprevisíveis e, portanto estamos limitados a sermos apenas uma coisa. Assim o tempo também é considerado em partes distintas, ora um passado, ora um presente, ora um futuro.

O pensamento complexo surge e transforma a compreensão de aprendizagem. Até então a idéia disciplinar dominava com a intenção de ser auto-suficiente com a capacidade de esgotar os conteúdos de sua especificidade, no entanto o que se esgotava era a compreensão da existência de comunicação entre as diferentes disciplinas (ou entre as diferentes realidades).

Para explicar com mais precisão os fenômenos do mundo foram surgindo cada vez mais disciplinas. Elas ganharam força, mas também ganharam a falta de sentido e como já fora citado, era a eficácia pela eficácia o que tornava o caminho estreito para um conhecimento que é complexo e envolve diferentes fatores.

O movimento de diálogo entre as disciplinas faz com que não ocorra hierarquia entre os saberes, todos elas são importantes para a construção de um raciocínio com reflexões que envolvam todas as conseqüências possíveis (pensadas ou não).

O conhecimento complexo é um fenômeno natural, ela deriva de nossa mente, que também é complexa, portanto devemos nos conscientizar e abrir as portas para novos rumos. A transdiciplinaridade não exclui as outras epistemologias, mas é um complemento delas. 


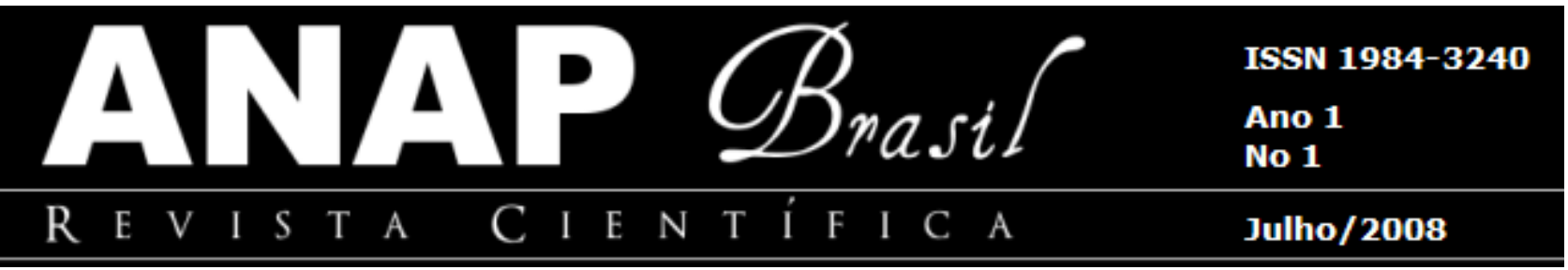

A idéia é sair de uma visão unilateral para uma visão multilateral, mas sem o fanatismo de achar que a transdiciplinaridade seja o único caminho e a única verdade, pelo contrario, esta proposta sugere a existência mútua de forma rigorosa e coerente de "mais de uma verdade", pois as combinações de realidade e de percepção da mesma são infinitas.

O mundo é relativo, não há normatizações e regras fechadas, os acontecimentos dependem das circunstâncias que nem sempre são as esperadas, e por isso devemos desenvolver a capacidade de compreender diferentes níveis de realidade não fechando nossa percepção em um único olhar. Somos sujeitos e objetos com conhecimentos que são ao mesmo tempo externos e internos e temos a capacidade de acessar essa compreensão.

Há um fato triste em nossa realidade, o homem é mortífero com seus diferentes, com seus iguais e até mesmo com suas ideologias.

A natureza que comporta uma biosfera diversificada e rica começou a sofrer terríveis mutações deste o momento em que um certo animal se tornou "racional", ela tem se modificado bruscamente, no entanto a força da natureza continua a mesma desde os inicio dos tempos.

Nossa espécie que também sofreu alterações desde o inicio é que enxerga a natureza de formas diferentes, em tempos diferentes da sua historia conforme seus valores vigentes. Nosso imaginário constrói realidades distintas pela direta influência do meio em que vivemos, ou seja, o grau de desenvolvimento da ciência e das técnicas, da organização social, da arte, da religião entre outros fatores conjuntamente nos influência para inventamos diferentes naturezas (percepções de realidades).

A linguagem hermenêutica das ciências reduz o numero de interessados pelas suas teorias, e o exoterismo barato levam muitos a dispensarem o rigor reflexivo. Nicolescu alerta para este problema nas universidades:

[...]a moda universitária atual é reduzir tudo à linguagem: não haveria realidade, no sentido ontológico do termo, mas simplesmente linguagens que constroem uma realidade, e nem mesmo haveria ciência que explora a natureza, mas uma construção social daquilo que chamamos de "a ciência". Estas duas tendências exprimem, na verdade, a derrota da sociedade atual, mas elas se enfeitam com ornamentos atraentes da espiritualidade ou da honorabilidade acadêmica para esconde-la pudicamente. (Ibidem, pg.126) 


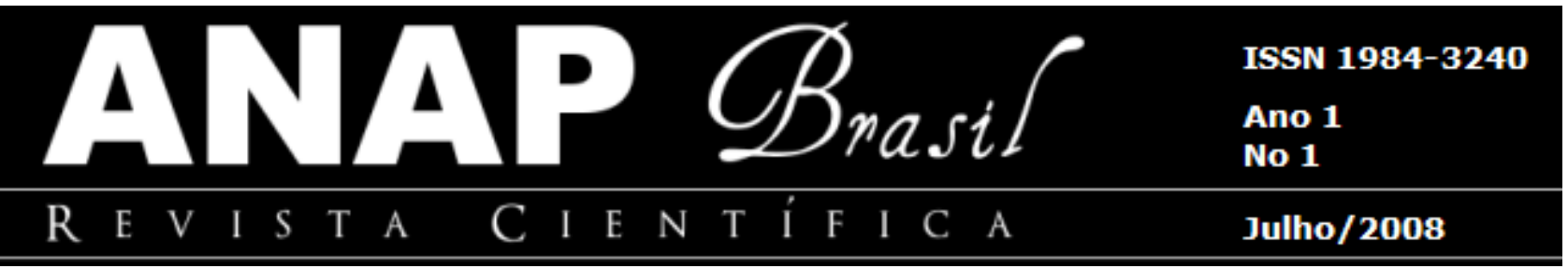

A transdiciplinaridade não levanta a bandeira de dona da verdade como já fora dito, pelo contrário, ela está sempre alertando para o recebimento de novas idéias, para a renovação de idéias já postas sem se submeter a um único caminho.

É o global integrando o local e seu contrário, é o abrangente integrando o especifico e vise-versa no movimento da transdiciplinaridade.

Todo este estudo, toda esta teoria para se materializar e estar presente na vida de todos, deve ser inserida no cotidiano, coisa que só ocorre se houver transformação do pensamento, da reflexão, resultado obtido através de um trabalho educativo.

Milagre educacional não existe, mas é necessário transformar a educação atual que alimenta um planeta imerso no egoísmo e na competitividade.

Um mundo diferente do que temos é a ambição da transdiciplinaridade, e ele está construído na idéia da abertura do pensamento, da aceitação às diferentes realidades com respeito aos seres que vivem no planeta.

\section{CONCLUSÃO}

A vida como conhecemos ocorre numa escala tão ínfima que podemos dizer que somos um milagre, desta forma devemos lutar para continuar na condição de seres milagrosos, para isso somente uma visão infinita do todo nos fará compreender nossas forças, nossas capacidades, nossas inteligências. Elas não são limitadas, portanto não podemos aceitar uma visão de mundo limitada como a que vivemos à alguns séculos.

Falar de ecologia, de filosofia e educação significa falar de seres humanos, portanto podemos dizer que um pensamento hermenêutico é um pensamento transdiciplinar pois está além daquilo que temos e além daquilo que conhecemos o que o torna também é algo milagroso.

Pensar na física quântica, na possibilidade de diferentes níveis de realidade traz uma idéia de "não somos nada", ao mesmo tempo em que "somos tudo". 


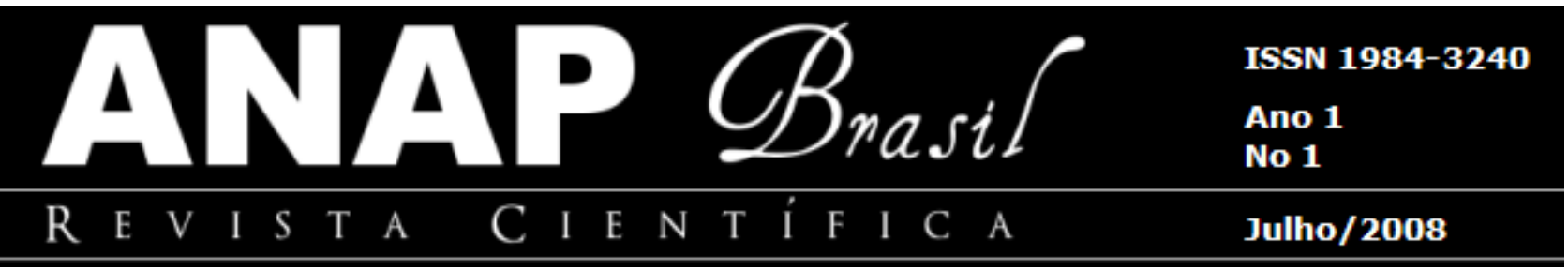

Se sabemos que existe no Universo inteiro a mesma substância que há no corpo de um bebê, ou num livro acadêmico então qual a dificuldade de compreendermos que somos tudo uma coisa só? E porque insistimos em ficar apenas com nosso lado racional? Porque não damos valor àquilo que somos e fato? Seres complexos, que amam e que gostam de serem amados. Seres que sabem que um por do sol é muito mais que raios ultravioletas advindo de uma estrela morta.

Antes víamos o mundo com um olhar temeroso, não entendíamos os fenômenos que nos cercavam e isto de certa forma nos colocava em posição de submissão ao planeta, depois fomos conseguindo não só entender e classificar os fenômenos como também controlá-los, o que nos fez alimentar uma ilusão estúpida de superioridade ao planeta. Perdemos desta forma o respeito por tudo, pela natureza e por nós mesmos.

Temos que modificar o paradigma em que nos encontramos, temos que quebrar com a idéia de que o planeta é um produto para ser consumido, não devemos voltar a ter medo, devemos resgatar o respeito.

Enfim, é preciso quebrar com nosso egocentrismo, é preciso quebrar com o sistema curricular que nos tornou tão fragmentados como um copo em pedaços espalhados no chão de mármore.

A educação pode sim ser ajudada pela filosofia para compreender os temas ambientais. Um dialogo transdiciplinar na perspectiva da sustentabilidade de toda raça humana e a todo o planeta.

\section{REFERÊNCIAS}

ARAUJO, Pedro Bezerra de. Paidéia. São Paulo. Scottecci, 1998.

AZEVEDO, Murillo N. Ecologia Mental. São Paulo. Pensamento, 1995.

CAPRA, Fritjot. As conexões ocultas - ciência por uma vida sustentável. São Paulo, Cultrix, 2002.

. O ponto de mutação. São Paulo. Cultrix, 1999.

CARVALHO, Isabel C. M. Educação Ambiental - A formação do sujeito ecológico. São Paulo. Cortez, 2004. 


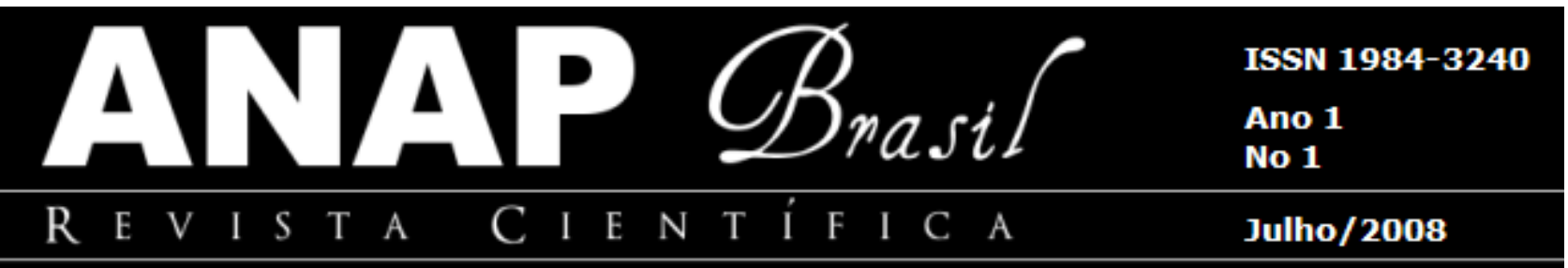

A invenção do sujeito ecológico: identidade e subjetividade na formação dos educadores ambientais. In: Sato, M. \& Carvalho, I. (org.). Educação Ambiental- pesquisas e desafios. Porto Alegre. Artmed, 2005.

GAUDIANO-GONZÁLEZ, E. Interdisciplinaridade e educação ambiental: explorando novos territórios epistemológicos. In: Sato, M. \& Carvalho, I. (org.). Educação Ambiental- pesquisas e desafios. Porto Alegre. Artmed, 2005.

GRÜN, Mauro. Ética e educação ambiental - A conexão necessária. Campinas. Papirus, 1996.

. O conceito de holismo em ética ambiental e em educação ambiental. In:

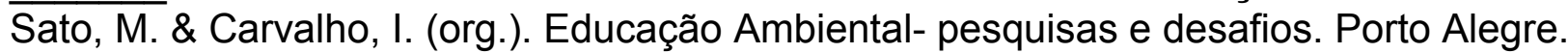
Artmed, 2005.

GUATTARI, Félix. As três ecologias. Campinas. Papirus1990.

HERMANN, Nádia. Hermenêutica e educação. Rio de Janeiro. DP\&A, 2003.

JACOBI, P.R. Educação Ambiental: o desafio da construção de um pensamento crítico, complexo e reflexivo. Educação e pesquisa, v.31,n.2, p.233-250, ago.2005.

JUNIOR, Oswaldo G. Um direito próprio da natureza? Notas sobre ética, direito e tecnologia. Fragmentos de Cultura. Goiânia, v.14, n4, p. 637-654, abr.2004.

LOVELOCK, James. As eras de Gaia - A biografia da nossa Terra viva. Rio de Janeiro. Campus, 1991.

NICOLESCU, Bassarab. O manifesto da Transdiciplinaridade. São Paulo. Triom, 1999.

PELIZZOLI, Marcelo L. A emergência do paradigma ecológico. Rio de Janeiro. Vozes, 1999.

MERLEAU-PONTY, M. A fenomenologia da percepção. São Paulo. Martins Fontes, 2006.

SANTOS, Marcos F. Crepusculário. São Paulo. Zouk, 2005.

SAUVÉ, L. Uma cartografia das correntes em educação Ambiental. In: Sato, M. \& Carvalho, I. (org.). Educação Ambiental- pesquisas e desafios. Porto Alegre. Artmed, 2005.

SEVERINO, Antonio J. Metodologia do trabalho cientifico. São Paulo. Cortez, 2002. 